\title{
Temporary Endobronchial Embolization with Silicone Spigots for Moderate Hemoptysis: A Retrospective Study
}

\author{
O. Bylickia,b T. Vandemoortele ${ }^{a, c}$ S. Laroumagne ${ }^{a} \quad$ P. Astoul ${ }^{a} \quad$ H. Dutau ${ }^{a}$

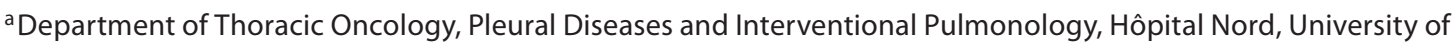 \\ the Mediterranean, Marseille, ${ }^{b}$ Pulmonary Department, Desgenettes Military Hospital, Lyon, France; ${ }^{\mathrm{c}}$ Department of \\ Pulmonology, Centre Hospitalier de I'Université de Montréal Hôpital Notre-Dame, Montreal, Qué., Canada
}

\section{Key Words}

Bronchoscopy - Endobronchial embolization •

Hemoptysis • Endobronchial spigot

\begin{abstract}
Background: The management of airway bleeding is generally performed in an emergency to prevent hypoxemia and lung flooding. When the bleeding arises from peripheral lesions that are not visible endoscopically, bronchoscopic options have limited curative intents. Endobronchial embolization using silicone spigots (EESS) is a novel approach. Objectives: We analyzed the efficacy and safety of EESS in a retrospective study. Methods: We retrospectively reviewed charts of patients referred to our center for moderate hemoptysis (MH) who underwent EESS. Successful management is defined as immediate bleeding cessation. Results: From December 2008 to January 2012, 9 patients were treated with EESS in our endoscopy unit. The $\mathrm{MH}$ originated from the left upper lobe in 4 cases, the right upper lobe in 3 cases and the right middle lobe and left lower lobe in 1 case each. Thirteen spigots were inserted. The success rate was $78 \%$. Of the 9 patients, 7 were referred to interventional radiology for bronchial artery embolization, with a success rate of $86 \%$, and 2 were referred for thoracic surgery. One patient had
\end{abstract}

EESS as definitive treatment; the silicone spigots were bronchoscopically removed after a median of 4 days in 6 of the remaining 8 patients. Only 2 patients had hemoptysis recurrence after a median follow-up of 107 days (ranging from 13 to 1,017 days). None of the patients died from hemoptysis. Conclusion: EESS is an original, temporary technique that requires only a flexible bronchoscope and biopsy forceps for placement and removal. EESS ensures airway protection while waiting for definitive management.

Copyright @ 2012 S. Karger AG, Basel

\section{Introduction}

Hemoptysis is a frequently encountered symptom in a pulmonologist's practice, with a spectrum ranging from blood-streaked sputum to major bleeding, which may be life-threatening. It represents $15 \%$ of pulmonary admissions [1]. There is no consensus on the definition of severity based on volume and flow, the respiratory and hemodynamic impact, the presence of respiratory and cardiovascular comorbidities and the requirement of vasoconstrictors [2, 3]. Moderate hemoptysis $(\mathrm{MH})$ can be defined as a sputum volume between 50 and $200 \mathrm{ml} / 24 \mathrm{~h}$ [4]. Bronchoscopy is an essential part of management be-

\section{KARGER}

Fax +4161306 1234

E-Mail karger@karger.ch

www.karger.com (c) 2012 S. Karger AG, Basel

0025-7931/12/0843-0225\$38.00/0

Accessible online at:

www.karger.com/res
Hervé Dutau, MD

Thoracic Oncology, Pleural Diseases and Interventional Pulmonology

Hôpital Nord, Chemin des Bourrely

FR-13326 Marseille Cedex 20 (France)

Tel. +33 4919659 87, E-Mail herve.dutau@ap-hm.fr 


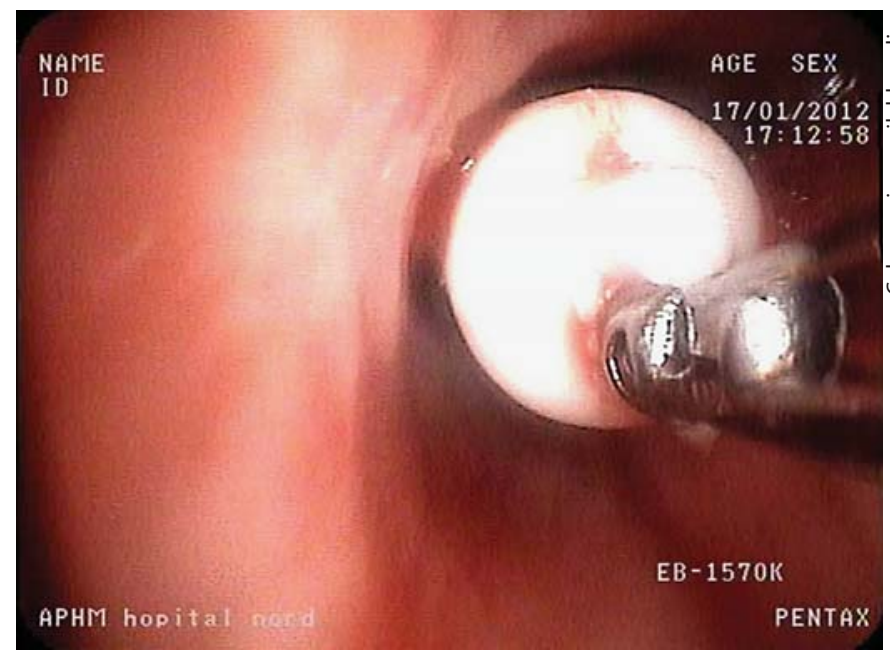

Fig. 1. Silicone spigot being grasped by forceps.

Table 1. Patient characteristics

\begin{tabular}{ll}
\hline Male/female & $4 / 5$ \\
Etiology & \\
$\quad$ Lung cancer & $4(44.4 \%)$ \\
$\quad$ Unknown & $3(33.3 \%)$ \\
$\quad$ Bronchiectasis & 1 \\
$\quad$ Overdose of anticoagulant & 1 \\
Other cofactor & \\
$\quad$ Antiplatelet & 2 \\
Hemoglobin before EESS, g/l & 118.7 \\
Hemoglobin after EESS, g/l & 107.1 \\
\hline
\end{tabular}

cause it allows localization of the hemoptysis origin and endoscopic treatment for lesions that are accessible [5]. When the bleeding is from peripheral lesions, bronchoscopic options are few and have limited curative intent, generally preceding radiological or surgical management [6-10]. Endobronchial embolization with silicone spigots (EESS) is an alternative technique that allows the occlusion of the bronchus, the source of the bleeding, thereby securing an airway until definitive treatment can take place [11]. We report our experience in EESS for MH.

\section{Patients and Methods}

All patients undergoing placement of a silicone spigot (endobronchial Watanabe spigot, EWS ${ }^{\circledR}$, Novatech, La Ciotat, France) for $\mathrm{MH}$ at our interventional endoscopy unit were included in this retrospective study, and their charts were reviewed. All silicone spigots were placed between December 2008 and January 2012 for hemoptysis. MH was defined as hemoptysis of $50-200 \mathrm{ml} / 24 \mathrm{~h}$ without being life-threatening. Flexible bronchoscopy confirmed the diagnosis of hemoptysis and allowed localization of the source of bleeding. In the absence of a macroscopic bleeding lesion that could be amenable to direct treatment and in the case of continued bleeding despite symptomatic local treatment (cold-saline lavage or topical vasoconstrictive agents), the patient was eligible for EESS. Massive hemoptysis was not included in this study since it is not treatable with EESS. This is due to the fact that the bronchoscope working channel is filled with the biopsy forceps, preventing efficient suctioning of blood and the clear visualization of the bronchi.

We recorded patients' demographic data (age and gender) and endoscopic findings (localization of hemoptysis), the size and number of silicone spigots, the delay of bronchial artery embolization, the duration of silicone spigot placement, the outcome and the overall survival duration. Follow-up on all patients was available up to January 31, 2012, including physician assessment 1 month after treatment, and we calculated survival based on the date of EESS.

In our study, all silicone spigots were placed with the patient under general anesthesia. All patients were intubated with a rigid bronchoscope which is systematic in our practice when encountering hemoptysis.

When the decision was taken to embolize the segmental bronchus using silicone spigots, it was done with a flexible bronchoscope through the rigid bronchoscope. For insertion, biopsy forceps were introduced through the flexible bronchoscope and the spigot was grasped. The entire unit was then inserted through the rigid bronchoscope (fig. 1). Under direct visual guidance, the spigot was placed in order to block either the segmental or the subsegmental bronchus completely and to prevent further bleeding into the more proximal airways. The spigot size was chosen accordingly: $7 \mathrm{~mm}$ for a segmental bronchus and 5 or $6 \mathrm{~mm}$ for a subsegmental airway. Placement of more than one spigot was maybe necessary to achieve adequate hemostasis. Successful management was defined as immediate bleeding cessation. After EESS, a multidisciplinary discussion (held by the radiologist, chest physician and thoracic surgeon) decided whether the next therapeutical step for that patient would be bronchial artery embolization or thoracic surgery.

Approval was obtained from the local institutional review board 'Hôpital Nord Ethical Committee' for this retrospective chart study.

\section{Results}

From December 2008 to January 2012, 9 patients were treated with EESS in our endoscopy unit. They were all included in this retrospective study. The median age was 65.5 years (table 1 ) and the series comprised 5 women and 4 men. The etiology of $\mathrm{MH}$ was known in 6 cases (with a majority of lung cancer) and 3 were unknown (table 1). Four patients with lung cancer were undergoing chemotherapy when they presented with $\mathrm{MH}$. Overdose of an- 
Table 2. Demographic characteristics and other relevant data

\begin{tabular}{|c|c|c|c|c|c|c|c|c|c|c|c|c|}
\hline $\begin{array}{l}\text { Patient } \\
\text { No./age/ } \\
\text { gender }\end{array}$ & Etiology & $\begin{array}{l}\text { Date of } \\
\text { bronchos- } \\
\text { copy }\end{array}$ & $\begin{array}{l}\text { Locali- } \\
\text { zation }\end{array}$ & $\begin{array}{l}\text { Spigot } \\
\text { size, } \mathrm{mm}\end{array}$ & $\begin{array}{l}\text { Number } \\
\text { of } \\
\text { spigots }\end{array}$ & $\begin{array}{l}\text { Hemop- } \\
\text { tysis } \\
\text { cessation }\end{array}$ & $\begin{array}{l}\text { Delay before } \\
\text { embolization } \\
\text { days }\end{array}$ & $\begin{array}{l}\text { Success } \\
\text { after } \\
\text { emboli- } \\
\text { zation }\end{array}$ & $\begin{array}{l}\text { Recur- } \\
\text { rence }\end{array}$ & $\begin{array}{l}\text { Other } \\
\text { hemostatic } \\
\text { action }\end{array}$ & $\begin{array}{l}\text { Duration } \\
\text { of spigots } \\
\text { in place } \\
\text { days }\end{array}$ & $\begin{array}{l}\text { Follow- } \\
\text { up } \\
\text { months }\end{array}$ \\
\hline $1 / 48 / \mathrm{M}$ & overdose & 18.06.2010 & LLL & 6 & 1 & yes & same day & yes & no & - & 4 & 19.4 \\
\hline $2 / 56 / \mathrm{F}$ & unknown & 07.10 .2011 & LUL & 5 & 1 & yes & 11 & yes & no & - & 12 & 14.3 \\
\hline $3 / 83 / \mathrm{F}$ & unknown & 24.08 .2010 & LUL & 5 & 3 & yes & 4 & yes & no & - & 8 & $1.2^{\mathrm{a}}$ \\
\hline $5 / 72 / \mathrm{M}$ & lung cancer & 19.05 .2011 & RUL & 6 & 2 & yes & - & - & - & - & $\begin{array}{l}210 \text { (still } \\
\text { in place) }\end{array}$ & 8.44 \\
\hline $6 / 77 / F$ & lung cancer & 30.11 .2011 & LUL & 6 & 1 & no & 6 & yes & yes & $\begin{array}{l}\text { Cyanoacrylate } \\
\text { glue }\end{array}$ & 14 & $2.03^{\mathrm{a}}$ \\
\hline $7 / 75 / \mathrm{F}$ & bronchiectasis & 30.12 .2011 & RML & 7 & 1 & yes & same day & yes & no & - & 4 & 1.01 \\
\hline
\end{tabular}

$\mathrm{LLL}=$ Left lower lobe; $\mathrm{LUL}=$ left upper lobe; RUL = right upper lobe; $\mathrm{RML}=$ right middle lobe.

a Deceased.

ticoagulation therapy (Fluindione) had occurred in a dialyzed patient for long-term chronic renal failure with chronic atrial fibrillation. One patient had $\mathrm{MH}$ secondary to bronchiectasis. The $\mathrm{MH}$ originated from the left upper lobe in 4 cases, the right upper lobe in 3 and the right middle lobe and left lower lobe in 1 case each (table 2).

A total of 13 silicone spigots were placed in 9 patients (table 2). We used a single endoscopic Watanabe spigot for 6 patients and 2 spigots each for 2 others. One patient required 3 spigots for 3 successive endoscopies because of persistent hemoptysis after arterial embolization. Successful management, defined as the immediate cessation of bleeding during bronchoscopy, occurred in 7 patients (78\% of cases). Of the 13 silicone spigots inserted, 11 were successful in achievingd hemostasis (85\%), and only 2 failed to control the bleeding. The 2 failures were due to the inability to embolize the bronchus because of difficult bronchial anatomy. In these patients, hemoptysis originated from the apical segment of the upper lobes ( 1 left and 1 right).

Of the 9 patients, 7 were then referred to interventional radiology for bronchial artery embolization, with a success rate of $86 \%$. Two patients were referred to thoracic surgery for lobectomy. One patient (No. 4) underwent lobectomy for hemostasis after arterial embolization failure because of a dissection of a bronchial artery during the procedure and the persistence of hemoptysis despite 3 successive EESS. The other patient (No. 9) underwent a lobectomy with both a curative (lung cancer) and hemostatic intent (fig. 2). The spigots were removed along with the tumor.

One patient, suffering from right upper lobe lung cancer, did not require any other treatment after EESS. At 6 months, both spigots were still in place and led to right upper lobe atelectasis (fig. 3).

For the remaining patients, the spigots were bronchoscopically removed after a median of 4 days [1-11] in 6 of them. In 1 patient, there was evidence of endobronchial migration with subsequent expectoration of the silicone spigots, without a recurrence of bleeding.

Only 2 patients (Nos. 4 and 6) presented with hemoptysis recurrence after a median follow-up of 107 days (ranging from 13 to 1,017 days). Hemoptysis recurred after removal of the silicone spigots despite prior arterial embolization in patient No. 6. Endobronchial embolization with Cyanoacrylate glue in the left upper apical lobe was subsequently successfully performed.

None of the patients died from hemoptysis. There were no per-procedure complications arising from EESS. One spigot migrated 5 days after insertion without adverse effects. Antibiotic prophylaxis with amoxicillin and clavulanic acid was carried out in 4 patients. None of the 7 patients had fever or infection. 

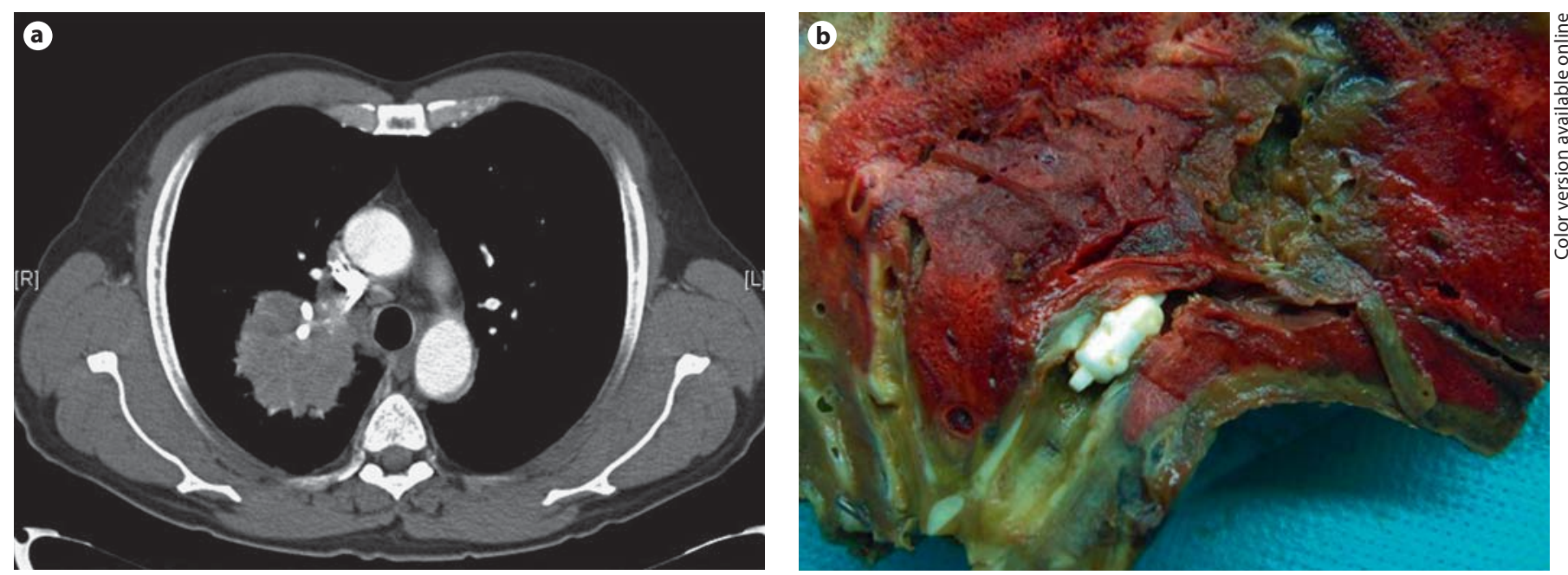

Fig. 2. Case No. 9. a CT scan showing 2 spigots in the right upper lobe. b Histological section after lobectomy: spigots up in the segmental bronchus.
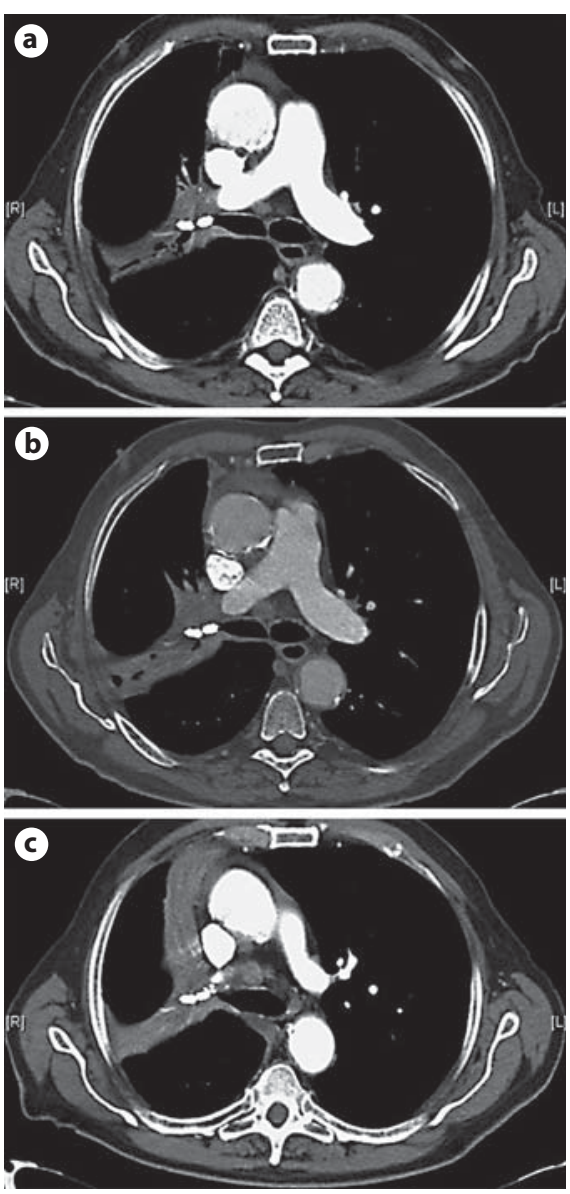

Fig. 3. Case No. 5. CT scan after 1 month (a), 3 months (b) and 6 months (c). Two spigots are present in the right upper lobe.

\section{Discussion}

EESS has been described in different airway conditions, such as bronchopleural fistulas [12], but in only 1 other report has it been used in the management of hemoptysis [13]. This previous report was from a patient treated in our unit for massive hemoptysis, but not included in this study.

Among the endoscopic treatment options for hemoptysis, one can differentiate between chemical treatments and mechanical treatments. Local instillation of topical vasoconstrictive agents in the bleeding airway can be effective in mild-to-moderate hemoptysis [14]. Use of the antifibrinolytic drug tranexamic acid within the bronchial tree has been described in 2 patients [15]. Endoscopic instillation of a fibrinogen-thrombin combination can be used for patients in whom bronchial arterial embolization is contraindicated [16]. None of these methods ensures airway protection in the case of recurrence. All of our patients were treated with cold saline in order to decrease the bleeding and allow optimal visualization for EESS. Indeed, EESS is virtually impossible in a case of active bleeding.

Insertion of a balloon catheter in the bleeding bronchus using a flexible bronchoscope is a well-known tamponade technique $[17,18]$. One limitation of this technique is that patients require tracheal intubation and mechanicalventilation while waiting for definitive treatment.

Brandes et al. [19] described the use of an endobronchial stent tamponade in a patient with massive hemop- 
tysis in order to bypass a bleeding bronchus. Recently, local wicking techniques with a cellulose derivative using a rigid bronchoscope have been reported [20]. Endobronchial application of $n$-butyl cyanoacrylate, a biocompatible adhesive that solidifies on contact with humidity, has proven effective in controlling mild hemoptysis [21]. Injection of biological glue has also been described [22].

Unlike endobronchial glue injection, EESS is a completely reversible treatment. Another merit of the technique, unlike balloon tamponade, could be that endobronchial obstruction is limited to a subsegment of the bronchial tree and the remaining airways can participate in ventilation allowing optimal respiratory status. No patient in our study needed to be admitted to a critical care unit for monitoring.

Available endoscopic techniques for macroscopically visible central lesions such as laser photocoagulation [23, 24], argon plasma coagulation [25], electrocautery [26] and cryotherapy [27] cannot be used when the bleeding arises from peripheral lesions.

The spigot is a silicone plug presented in 3 different diameters $(5,6$ or $7 \mathrm{~mm})$ (fig. 1). This spigot was first described in the management of bronchopleural fistulas [12]. Temporary endobronchial embolization with a silicone blocker has been described in the treatment of bronchopleural fistula and in some cases of endoscopic lung volume reduction $[12,28]$.

This technique has several advantages over others. The method is reversible, with the introduction of temporary spigots under visual control. After placement, the spigot requires no further handling. All patients in our series were extubated immediately after the procedure. None of the 9 patients presented respiratory distress or other complications that require continuous monitoring.

To our knowledge, there are only 2 studies on the use of silicones spigots: in the management of bronchopleural fistula and pneumothorax $[29,30]$. The complication rate in the study of Sasada et al. [30] was $45 \%$ (11/24) including 4 migrations, 3 cases of pneumonia and 3 of pulmonary atelectasis. This rate is more striking than in our study, but the patients in their study had many comorbidities and EESS was achieved after several days of bed rest with chest drainage. Even though most of our patients suffered from lung cancer, in terms of comorbidities, our population was not comparable with theirs.

Successful management, defined as the immediate cessation of bleeding during bronchoscopy, occurred in 7 patients. This confirms the efficacy of EESS in achieving immediate hemostatic control. Two patients had hemoptysis recurrence after spigot removal. This illustrates the efficacy of EESS in preventing recurrence while waiting for a definitive treatment, or sometimes when the definitive treatment is not successful. In some cases, EESS may be technically difficult in cases of the hemoptysis originating from the apical segment of the upper lobes, as described in our series. One other limitation is that some segmental bronchi can be too small to allow the insertion of the spigots. Ablation of silicone spigots poses no problem. Following our first experience with EESS, modifications and improvements have been proposed to the manufacturer in order to optimize the technique. The main modification would be to pierce a tiny hole in the spigot, enabling a metallic guide-wire to pass through and direct it in the bleeding segment. These changes would facilitate the insertion of spigots, especially in upper lobes, and decrease operating time.

\section{Conclusion}

EESS is an original, temporary technique that requires only a flexible bronchoscope and biopsy forceps for placement and removal. EESS allows airway protection while waiting for definitive management. It has its place in the therapeutic armament of hemoptysis. Modifications of silicone spigots will enable better use and a generalization of this technique.

References monary physician in critical care, illustrative case 7: assessment and management of massive haemoptysis. Thorax 2003;58:814-819.

$\checkmark 2$ Ibrahim WH: Massive haemoptysis: the definition should be revised. Eur Respir J 2008; 32:1131-1132.

3 Mal H, Rullon I, Mellot F, Brugiere O, Sleiman $\mathrm{C}$, Menu Y, et al: Immediate and longterm results of bronchial artery embolization for life-threatening hemoptysis. Chest 1999; 115:996-1001.

4 Corey R, Hla KM: Major and massive hemoptysis: reassessment of conservative management. Am J Med Sci 1987;294:301-309.

5 Dweik RA, Stoller JK : Role of bronchoscopy in massive hemoptysis. Clinics Chest Med 1999;20:89-105.

6 Remy J, Arnaud A, Fardou H, et al: Treatment of hemoptysis by embolization of bronchial arteries. Radiology 1977;122:33-37.

-7 Swanson KL, Johnson M, Prakash UBS, McKusick MA, Andrews JC, Stanson AW: Bronchial artery embolization, experience with 54 patients. Chest 2002;121:789-795. 
$>8$ Crocco JA, Rooney JJ, Fankushen DS, et al: Massive hemoptysis. Arch Intern Med 1968; 121:495-498.

9 Garzon AA, Gourin A: Surgical management of massive hemoptysis: a ten-year experience. Ann Surg 1978;187:267-271.

$\checkmark 10$ Fartoukh M, Khalil A, Louis L, et al: An integrated approach to diagnosis and management of severe haemoptysis in patients admitted to the intensive care unit: a case series from a referral centre. Respir Res 2007;8:1120.

11 Dutau H, Palot A, Haas A, Decamps I, Durieux O: Endobronchial embolization with a silicone spigot as a temporary treatment for massive hemoptysis. Respiration 2006;73: 830-832:301-309.

12 Watanabe Y: LVRS with WBA. World Congress of Bronchology, Boston, 2002.

13 Sakr L, Dutau H. Massive hemoptysis: an update on the role of bronchoscopy in diagnosis and management. Respiration 2010;80:3858.

$\checkmark 14$ Breuer H, Charchut S, Worth H, Trampisch HJ, Glanzer K: Endobronchial versus intravenous application of the vasopressin derivative glypressin during diagnostic bronchoscopy. Eur Resp J 1989;2:225-228.

15 Solomonov A, Fruchter O, Zuckerman T, Brenner B, Yigla M: Pulmonary hemorrhage: a novel mode of therapy. Respir Med 2009; 103:1196-1200.

-16 Tsukamoto T, Sasaki H, Nakamura H: Treatment of hemoptysis patients by thrombin and fibrinogen-thrombin infusion therapy using a fiberoptic bronchoscope. Chest 1989; 96:473-476.
17 Freitag L: Development of a new balloon catheter for management of hemoptysis with bronchofiberscope. Chest 1993;103:593.

18 Kato R, Sawafuji M, Kawamura M, Kikuchi K, Kobayashi K: Massive hemoptysis successfully treated by modified bronchoscopic ballon tamponade technique. Chest 1996; 109:842-843

19 Brandes JC, Schmidt E, Yung R: Occlusive endobronchial stent placement as a novel management approach to massive hemoptysis from lung cancer. J Thorac Oncol 2008;3: 1071-1072.

20 Valipour A, Kreuzer A, Koller H, Koessler W, Burghuber OC: Bronchoscopy-guided topical hemostatic tamponade therapy for the management of life-threatening hemoptysis. Chest 2005;127:2113-2118.

21 Bhattacharyya P, Dutta A, Samanta AN, Chowdhury SR: New procedure: bronchoscopic endobronchial sealing; a new mode of managing hemoptysis. Chest 2002;121: 2066-2069.

22 De Gracia J, de la Rosa D, Catalan E, et al: Use of endoscopic fibrinogen-thrombin in the treatment of severe hemoptysis. Respir Med 2003;97:790-795.

23 Dutau H, Breen DP: Endobronchial laser treatment: an essential tool in therapeutic bronchoscopy; in Strausz J, Bolliger CT (eds): Interventional Pulmonology, European Respiratoy Monograph 48. Sheffield, European Respiratory Society, 2010, pp 149-160.
24 Bolliger CT, Sutedja TG, Strausz, Freitag L: Therapeutic bronchoscopy with immediate effect: laser, electrocautery, argon plasma coagulation and stents. Eur Respir J 2006. 27: 1258-1271.

25 Morice RC, Ece T, Ece F, Keus L: Endobronchial argon plasma coagulation for treatment of hemoptysis and neoplastic airway obstruction. Chest 2001;119:781-787.

26 Homasson JP: Endobronchial electrocautery. Semin Respir Crit Care 1997;18:535543.

27 De Weerdt S, Noppen M, Remels L, Vanherreweghe R, Meysman M, Vincken W: Successful removal of a massive endobronchial blood clot by means of cryotherapy. J Bronchol 2005; 12:1:23-24.

28 Sasada S, Tamura K, Chang YS, Okamoto N, Matsuura Y, Tamiya M, Suzuki H, Uehara N, Kobayashi M, Hirashima T, Kawase I: Clinical evaluation of endoscopic bronchial occlusion with silicone spigots for the management of persistent pulmonary air leaks. Intern Med 2011;50:1169-1173.

29 Watanabe Y, Matsuo K, Tamaoki A, Kamoto R, Hiraki S: Bronchial occlusion with endobronchial Watanabe spigot. J Bronchol 2003; 10:264-267.

30 Sasada S, Tamura K, Chang YS, Okamoto N, Matsuura Y, Tamiya M, Suzuki H, Uehara N, Kobayashi M, Hirashima T, Kawase I: Clinical evaluation of endoscopic bronchial occlusion with silicone spigots for the management of persistent pulmonary air leaks. Intern Med 2011;50:1169-1173. 